\title{
Differences in Mental Health, Help-Seeking and Barriers to Care Between Civilians and Sworn Members Working in Law Enforcement: A Research Note
}

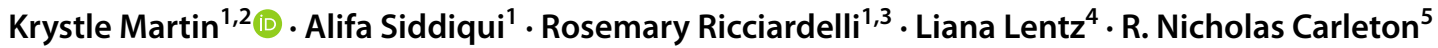

Accepted: 4 February 2021 / Published online: 27 February 2021

(c) The Author(s) 2021

\begin{abstract}
Recent Canadian research indicates $44.5 \%$ of public safety personnel (PSP) self-report symptoms consistent with at least one type of mental disorder; however, researchers have typically not focused on the mental wellness of civilians working within PSP sectors. Given that the number of civilians working in Canadian law enforcement organizations has doubled since 2003, with more than $30 \%$ of all police personnel in Canada being civilians, more research is needed to support this understudied sub-population within law enforcement. The current study used a survey to compare civilian members $(n=80)$ and sworn $(n=112)$ police officers working within a law enforcement organization on issues regarding mental disorders, perceived barriers to care and help-seeking behaviours. Results indicate that civilian members self-report a high prevalence of mental disorders and lower resilience compared with police officers in the same organization. Civilians reported similar barriers to accessing mental health compared with police officers but were less likely to indicate willingness to access supports within their place of employment. Our results support the need for equitable access to mental health resources for civilian staff working within law enforcement organizations.
\end{abstract}

Keywords Policing $\cdot$ Mental health $\cdot$ Civilian $\cdot$ Well-being $\cdot$ Help-seeking

Public safety personnel (PSP) include border services officers, communications officials (e.g. call centre operators, 911 operators), correctional workers, firefighters, paramedics and police officers. PSP appear at higher risk for exposures to potentially psychologically traumatic events compared with the general public (Carleton et al. 2019). The frequency of exposures to said events may

Krystle Martin

martink@ontarioshores.ca

1 Ontario Shores Centre for Mental Health Sciences, Whitby, Canada

2 Faculties of Health Sciences and Social Science and Humanities, University of Ontario Institute of Technology, Oshawa, Canada

3 Department of Sociology, Faculty of Humanities and Social Sciences, Memorial University of Newfoundland, St. John's, Canada

4 Western University, Canadian Institute for Public Safety Research and Training (CIPSRT), London, Canada

5 Anxiety and Illness Behaviours Laboratory, Department of Psychology, University of Regina, Regina, Canada help to explain higher rates of occupational stress injuries (Carleton et al. 2019) among PSP. Recent Canadian research indicates $44.5 \%$ of PSP self-report symptoms consistent with at least one type of mental disorder (Carleton et al. 2018); however, researchers have typically not focused on the potential impact of occupational stress injuries on civilians working within PSP sectors. Civilians in PSP organizations may not be directly involved in attending the scene of an accident, crime or other potentially psychologically traumatic events, but many are exposed to and manage information that is graphic or potentially psychologically traumatic (e.g. reviewing reports, organizing photos and analyzing data; Kiedrowski et al. 2017; Taylor et al. 2006). Accordingly, we designed the current study to help elucidate the experiences of civilians working in a law enforcement organization (LEO).

Civilians working in LEOs support sworn members (i.e. police officers) by providing clerical and administrative supports (McCarty and Skogan 2012), which can increase cost-effectiveness and field efficiencies of the organization (Ruddell and Jones 2014). Civilian roles have expanded to include behind the scenes work such as data analytics 
and crime mapping, as well as emerging areas of policing that support criminal investigations such as intelligence gathering (Council of Canadian Academics 2014). Civilians also work as communicators and dispatchers, support court proceedings and provide detention/cell block security. The number of civilians working in Canadian and other (e.g. USA, UK) LEOs has doubled since 2003 (Kiedrowski et al. 2017; Lentz et al. 2020), with over $30 \%$ of all LEO personnel in Canada being civilians (Conor et al. 2020).

Integrating civilians into police services can be challenging and may lead to different valuation of the roles civilians play in comparison with the valuation of the roles of their sworn counterparts (Bentley 2013; Taylor et al. 2006). In consequence, civilians may be left feeling like outsiders in their organizations (McCarthy and Skogan 2012), reporting morale problems and demonstrating increased staff turnover (Kiedrowski et al. 2017). Employee satisfaction surveys from LEOs indicate civilian staff may be less satisfied at work, less proud to work for their service, less likely to recommend their employer to others and are typically paid less (Kiedrowski et al. 2017).

Experiences of civilian personnel in LEOs may be relevantly different when considering potentially psychologically traumatic event exposures, help-seeking behaviour and well-being. Previous research with LEO participants indicates no differences between civilians and sworn members on self-reported burnout scores or correlates of burnout (McCarty and Skogan 2012). Reports of physical and psychological injuries in LEOs also appear comparable for civilians and sworn members (Kiedrowski et al. 2017). Results from studies with two Royal Canadian Mounted Police (RCMP) divisions indicate that civilian members were significantly more likely to screen positive for one or more mental health disorders than sworn members (Lentz et al. 2020). Despite the available results, anecdotal evidence suggests that many civilians working in LEOs are not provided mental health-focused training or education and may be excluded from critical incident debriefings.

All LEO personnel may be exposed to potentially psychologically traumatic events and there may be pervasive notions of a traumatic event hierarchy or exposure modality hierarchy (i.e. direct or vicarious) (Ricciardelli et al. 2020), despite evidence that no objective universal traumatic event hierarchies exist (Carleton et al. 2019). There may be anecdotal notions of categorizing direct rather than vicarious (e.g. reading, hearing, learning, conversing) potentially psychologically traumatic event exposures (Horsford 2012); accordingly, sworn members who are more regularly exposed directly to these types of events may be perceived as having more legitimate claims for occupational stress injuries than civilian members.

Research studies on understanding the well-being of LEO civilian members remain scant. The increased focus in Canada on supporting mental health among police (e.g. presumptive legislation, the national posttraumatic stress injury action plan; Public Safety Canada 2019) may warrant including LEO civilian members (Lentz et al. 2020) who may also be at increased risk for posttraumatic stress injuries in the workplace through vicarious potentially psychologically traumatic event exposures. We designed the current study to compare civilian and sworn members of a LEO on issues regarding mental disorders, perceived barriers to care and help-seeking behaviours.

\section{Methods}

\section{Study Design}

We collected the current study data through a quantitative survey as part of a larger project focused on LEO personnel well-being and evaluating a new mental health resource funded by the Ontario Ministry of Labour. ${ }^{1}$ Research ethics for the larger study was provided by the first author's review board (REB \#18-001) and all data was collected from May to June 2018.

\section{Recruitment and Data Collection}

All current staff-including both sworn and civilian members-from one large LEO in Ontario, Canada, were invited to voluntarily participate in the larger study. Potential participants were notified by email from the LEO and invited to access either an online survey or contact a representative of the research team to learn more about the study. Informed consent for participation was explained within the online invitation and individuals clicked 'yes' to indicate consent to participate before engaging in the survey. The online survey asked participants to self-report on their demographics, employment, mental health, mental health training, perceived access to mental health resources and willingness to access mental health resources. The online survey questions created by the authors and relevant to the current study are presented in Table 1 . Continuous data were analyzed using descriptive statistics including mean scores and proportions. Group differences were analyzed using chisquared analyses and $t$ tests.

\footnotetext{
${ }^{1}$ Sponsored under the Ontario Ministry of Labour's Occupational Health, Safety, and Prevention Innovation Program, a new mental health App was created to support the mental health and wellness for members of the law enforcement agency included in this study. The data included in this paper was used to inform the design and content of this App.
} 
Table 1 Relevant survey questions

Question
Have you ever been diagnosed with mental health disorder?
Are you currently concerned about your mental health? This might
include your mood, experience of anger, level/frequency of anxiety,
use of drugs or alcohol, etc.
Which of the following potential support resources do you feel you can
and would access if you needed help managing your mental health?
List: spouse, friends, family member, first responder or other public
safety personnel colleague(s), first Responder or other public safety
personnel leader(s)/supervisors, peer supporter, occupational health
nurse, family doctor, psychologist, psychiatrist, employee and family
assistance program personnel, religious or spiritual leader, internet.
What prevents you from seeking professional help? Check all that
apply.

How resilient do you feel you are to manage your mental health?

How do you feel your resiliency to manage mental wellness has changed over time?
Possible responses

Yes; no; prefer not to answer

Yes; somewhat; no

I can and would access as an early resource; I can access, but only as a last resort; I can access, but would never access; I don't have access, but would access as an early resource; I don't have access, but would access only as a last resort; I don't have access, but would never access; I don't know if I have access

I don't want others to know about my mental health; It will have a negative impact on my career; I don't have time; Most professionals don't understand police culture; I am ashamed about my mental health; Mental health should be dealt with on your own; I don't trust mental health professionals; The clinician will just ask me about my feelings and my childhood; I've had a bad help-seeking experience; I don't know where to get help; It won't help

Participants were instructed to move an indicator along a visual analog scale from 0 to 100 .

I am more resilient now than I was when I first started as a PSP; I am less resilient now than I was when I first started as a PSP; My resiliency has stayed the same since I first started as a PSP

\section{Participants}

The participating Ontario LEO reported employing 904 (74.6\%) sworn members and 307 (25.4\%) civilian members at the time of the study. Approximately $16 \%(N=192)$ of the LEO personnel responded to the survey. Participant responses included 80 civilian (90\% female) and 112 sworn (20.7\% female) members. Both civilian and sworn and civilian members were on average 44.70 years old $(S D=7.75)$ and most $(70.8 \%$ reported working in a LEO for at least 11 years (Table 2).

\section{Results}

Significantly more $(p=0.01)$ civilian members $(26.3 \%)$ self-reported having been diagnosed with a mental disorder (current or past) relative to sworn members $(17.0 \%)$, although it is unclear whether these diagnoses were provided by a licensed mental health professional. When asked if they were concerned about their mental health, responses were similar between sworn and civilian member participants at $20.5 \%$ and $20.3 \%$, respectively.

Help-seeking behaviours are presented in Table 3. Most participants indicated having access to and a strong willingness to access a psychologist, their family doctor, and their spouse for mental health support. Differences existed in where civilian members and sworn members would seek help. Sworn members were proportionally more likely than civilian members to access a colleague $(p=0.02)$, a designated peer supporter $(p=0.03)$, an occupational health nurse $(p=0.01)$ or a psychiatrist $(p=0.03)$. In contrast, civilian staff members were proportionally more likely than sworn members to access the Internet as a support resource $(p=0.05)$.

Table 2 Participant characteristics

\begin{tabular}{|c|c|c|}
\hline Variable & $\begin{array}{l}\text { Civilian mem- } \\
\text { bers } n(\%)\end{array}$ & Sworn members $n(\%)$ \\
\hline \multicolumn{3}{|l|}{$\operatorname{Sex}^{\mathrm{a}}$} \\
\hline Female & $72(90.0)$ & $23(20.7)$ \\
\hline Male & $8(10.0)$ & $88(79.3)$ \\
\hline \multicolumn{3}{|l|}{ Marital status } \\
\hline Single & $7(8.7)$ & $3(2.7)$ \\
\hline Separated or divorced & $10(12.5)$ & $11(9.8)$ \\
\hline Married & $57(71.3)$ & $95(84.8)$ \\
\hline Re-married & $6(7.5)$ & $3(2.7)$ \\
\hline Age mean (SD) & $44.5(8.7)$ & $44.8(6.98)$ \\
\hline \multicolumn{3}{|l|}{ Year(s) of experience } \\
\hline$<1$ year & $1(1.3)$ & $2(1.8)$ \\
\hline $1-3$ years & $10(12.5)$ & $5(4.5)$ \\
\hline $4-10$ years & $15(18.8)$ & $8(7.1)$ \\
\hline $11-20$ years & $33(41.3)$ & $62(55.4)$ \\
\hline$>20$ years & $21(26.3)$ & $35(31.3)$ \\
\hline
\end{tabular}

${ }^{\mathrm{a} O n e}$ person chose not to answer 
Table 3 Participant responses regarding potential support resources to help manage their mental health

\begin{tabular}{lll}
\hline & \multicolumn{2}{l}{$\begin{array}{l}\text { I have access and would } \\
\text { access, } n(\%)\end{array}$} \\
\cline { 2 - 3 } & Civilian & Sworn \\
\hline Psychologist & $70(88.6)$ & $96(89.0)$ \\
Family doctor & $68(85.0)$ & $88(80.0)$ \\
Spouse & $56(83.6)$ & $89(88.1)$ \\
Internet* & $59(73.8)$ & $62(58.5)$ \\
Family member & $57(71.2)$ & $71(66.4)$ \\
Friend & $56(70.0)$ & $89(81.7)$ \\
Psychiatrist* & $42(63.6)$ & $72(70.6)$ \\
Employee and Family Assistance & $40(52.6)$ & $53(51.0)$ \\
$\quad$ Program (EFAP) & & $65(59.6)$ \\
Colleague* & $31(39.7)$ & $23(31.1)$ \\
Religious/spiritual leader & $14(27.5)$ & $39(37.1)$ \\
Peer supporter* & $14(19.4)$ & $21(19.1)$ \\
Supervisor/other work leader & $15(19.0)$ & $21(19.6)$ \\
Occupational health nurse* & $13(18.1)$ &
\end{tabular}

*Statistically significant differences between groups, $p<.05$

Barriers to mental health help-seeking are presented in Table 4. Barriers that were identified were related to privacy where civilian members (22.5\%) and sworn members (25.0\%) did not want others to know about their mental health status. Second, both civilian (16.7\%) and sworn (19.6\%) members comparably reported fearing that seeking help would have negative impacts on their career as the second barrier to mental health help-seeking. Other barriers to seeking mental health support included believing that mental health professionals do not understand police culture (civilian members $=11.5 \%$; sworn members $=12.5$ ) and not having enough time (civilian members $=15.4 \%$; sworn members $=8.9 \%$ ). There were no statistically significant differences between groups.
Participants were asked to self-report on their own resilience using a visual analogue scale ranging from not at all resilient $($ score $=0)$ to very resilient $($ score $=100)$. Sworn members reported significantly higher $(p=0.02)$ levels of resilience $(M=80.4, S D=18.3)$, compared with civilian members $(M=73.9, S D=20.7)$. Approximately one quarter of participating civilian members (29.5\%) and sworn members $(24.1 \%)$ reported their resilience had decreased since beginning work in a LEO.

Given the gender differences between the civilian and sworn groups ( $90.0 \%$ and $20.7 \%$ female, respectively), a separate analyses comparing the above mentioned variables between genders was done to determine if the differences we found could be attributed to the occupational status differences or if the differences were driven by gender alone. We found that there were no significant differences between males and females on any of the variables of interest with one exception: resilience. Participants who identified as female reported significantly lower $(p=0.01)$ resilience $(M=73.8, S D=21.4)$ compared with participants who identified as male $(M=81.6$, $S D=16.6)$.

\section{Discussion}

This study investigated civilian and sworn members of a LEO on issues regarding mental disorders, perceived barriers to care and help-seeking behaviours. Previously, researchers have tended to direct mental health attention for LEOs toward sworn members to the exclusion of civilian members (Alderden and Skogan 2012). The differential inclusions appear largely due to policing commonly being associated with law enforcement and interaction within the community (i.e. typically duties of sworn members) instead of its administrative and operational components (i.e. typically duties of civilian members; Dick and Metcalfe
Table 4 Participant responses regarding barriers to mental health help-seeking

\begin{tabular}{lll}
\hline Barrier & Group & \\
\cline { 2 - 3 } & Civilian $n(\%)$ & Sworn $n(\%)$ \\
\hline I don't want others to know about my mental health & $16(22.5)$ & $28(25)$ \\
It will have a negative impact on my career & $13(16.7)$ & $22(19.6)$ \\
I don't have time & $12(15.4)$ & $10(8.9)$ \\
Most professionals don't understand police culture & $9(11.5)$ & $14(12.5)$ \\
I am ashamed about my mental health & $3(3.8)$ & $7(6.3)$ \\
Mental health should be dealt with on your own & $4(5.1)$ & $2(1.8)$ \\
I don't trust mental health professionals & $3(2.8)$ & $4(3.6)$ \\
The clinician will just ask me about my feelings and my child- & $4(5.1)$ & $5(4.5)$ \\
$\quad$ hood & & $6(5.4)$ \\
I've had a bad help-seeking experience & $4(5.1)$ & $3(2.7)$ \\
I don't know where to get help & $3(3.8)$ & $4(3.6)$ \\
It won't help & $1(1.3)$ &
\end{tabular}


2001). Civilian members, however, may also be at increased risk for occupational stress injuries through vicarious potentially psychologically traumatic event exposures and therein may benefit from internal mental health resources typically only provided to sworn staff (e.g. Road to Mental Readiness (R2MR) and other resilience courses).

Participating civilian members reported a higher prevalence of having been diagnosed with a mental disorder than sworn members. This is supported by previous research (Lentz 2020). This study found that civilian members were less likely than sworn members to access organization-based supports (e.g. colleagues, designated peer supporters, the occupational health nurse) and were more likely to access online supports. Civilian members were also more likely than sworn members to report wanting to manage their mental health on their own while not knowing where to get help for mental health support.

Our current results suggest that participating LEO civilian members report less mental health knowledge and more mental health stigma than participating sworn members. Mental health knowledge, or literacy, is associated with both help-seeing behaviours and stigma. Krakauer et al. (2020) found that higher levels of mental health knowledge were associated with less stigma and more willingness to seek professional mental health services. Additionally, respondents who had experience with mental health in the past reported less stigma and increased mental health literacy (Dimoff and Kelloway 2019; Karaffa and Koch 2016). Experience with mental health may not refer to prior experience with compromised mental health but may translate to their normalizing of mental health need through discussion and training.

Other researchers have found that one in three first responders $(33.1 \%)$ experience stigma regarding mental health (Haugen et al. 2017), and that stigma is part of structural barriers to treatment seeking (Ricciardelli et al. 2018), so one may extrapolate from our results that a similar proportion of civilians in the observed LEO also experience stigma related to mental health.

Researchers have frequently identified stigma as a barrier that reduces mental health care-seeking (Clement et al. 2014; Haugen et al. 2017; Karaffa and Koch 2016). A recent systematic review of military and health professionals found that these populations were disproportionately deterred in help-seeking because of stigma, specifically stigma relating to employment-related discrimination, disclosure/confidentiality concerns and negative social judgement (Clement et al. 2014). The most commonly endorsed stigma items amongst PSP are fear of services not being confidential and that seeking psychological services would have a negative impact on one's career followed by feelings of judgment from coworkers and leadership (Haugen et al. 2017). These stigma are also indicated in the results of our survey.
Given the lower status in the LEO hierarchy of civilians, stigma in civilians working in LEOs may be exacerbated. Though civilian members are a part of and thus influenced by LEO culture, they feel viewed as less important than sworn members (Chess 1960; McCarty and Skogan 2012; Ratcliffe 2005). Such perceptions may lend to increased fear of seeking psychological assistance for civilian members who already feel inferior to sworn members. In consequence, civilian members may anticipate a more negative impact on their career if they seek treatment than the impact on the career of a sworn member.

Despite differences in help-seeking behaviours, civilian member participants responded similarly to their sworn counterparts when asked about the barriers to accessing professional mental health support. Worries include the impact on career, stigma and privacy. However, though not statistically significant, civilian member participants more frequently reported not knowing where to go for help, a lack of trust in mental health professionals, lack of time and feeling that mental health should be dealt with on one's own. Related to these identified barriers could be a lack of education regarding mental health in general or in the workplace.

Peer support programs are based on the premise that those who have endured and overcome an illness or disability can provide useful support, encouragement and hope to their peers (Walker and Bryant 2013). Peer support may be particularly valuable to civilians working in LEOs by having someone who understands their work and position within the organization from whom to seek help. Moreover, peer supporters with lived experience, researchers reveal, increase their credibility and in turn, makes them more trustworthy (Milliard 2020). Additionally, LEO's that provide civilian peer support may also increase users' sense of belonging within the organization by providing broader social networks (Walker and Bryant 2013) and social support, which has been shown to decrease depression and burnout (McCarty and Skogan 2012) while increasing resilience (McAllister and McKinnon 2009; Howe et al. 2012). Further research is required to determine if peer support would be helpful to civilians in LEOs and to increase the evidence-base of peer support in general (Walker and Bryant 2013).

The current study is not without limitations. Responses were collected from one municipal police service in Ontario and therefore are undoubtedly influenced by the specific characteristics of the service and are not necessarily generalizable to other LEOs or PSP groups. Similarly, our response rate was low and, given participation was voluntary, may not have been a representative group of employees. As participants could self-select to complete the survey, these individuals may have a particular interest in mental health, struggles in mental health, or were frustrated with the LEO's provision 
of mental health services, for example. Moreover, there were significant gender differences between the sworn and civilian groups with the majority of the sworn group comprising of males, while the civilian participants were overwhelmingly female. The gender balance in our sample is a true reflection of the service employees, and a common distribution of genders across these occupational roles within most Canadian LEOs, yet our study is limited in the gender insight we are able to provide. Therefore, future researchers should make efforts to explicitly seek data from male civilians and control for gender in statistical analyses to ensure that conclusions drawn can be confidently attributed to occupational role and not a result of gender. Given these factors, we need future research within LEO across the country to ensure that the current results are representative of Canadian LEO members working in civilian roles. We acknowledge that some staff members may have been reluctant to participate in the survey given possible skepticism about the information being kept confidential and fear of potential occupational repercussions given interpretations of stigma in policing culture. While a limitation, we believe it plagues most researchers in the area of policing.

\section{Conclusion}

Our study highlights some differences in mental health, help-seeking and barriers to care between civilians and sworn members working in law enforcement. This is especially important given that civilian members make up a significant portion of PSP organizations a recent Canadian study of civilians working within two LEOs reported higher rates of mental disorders compared with sworn members. Therefore, LEOs need to account for these results, considering how to best allocate mental health resources in a responsible manner to effectively support their workforce. More research is needed to address the scarcity of information available about civilians working within PSP organizations and their mental health.

Funding This project was funded by the Ontario Ministry of Labour, Occupational Health, Safety and Prevention Innovation Program.

\section{Declarations}

Ethical Approval All procedures performed in this study involving human participants were in accordance with the ethical standards of the institutional and/or national research committee and with the 1964 Helsinki declaration and its later amendments or comparable ethical standards.
Informed Consent Informed consent was obtained from all individual participants included in the study.

Conflict of Interest The authors declare that they have no conflict of interest.

Open Access This article is licensed under a Creative Commons Attribution 4.0 International License, which permits use, sharing, adaptation, distribution and reproduction in any medium or format, as long as you give appropriate credit to the original author(s) and the source, provide a link to the Creative Commons licence, and indicate if changes were made. The images or other third party material in this article are included in the article's Creative Commons licence, unless indicated otherwise in a credit line to the material. If material is not included in the article's Creative Commons licence and your intended use is not permitted by statutory regulation or exceeds the permitted use, you will need to obtain permission directly from the copyright holder. To view a copy of this licence, visit http://creativecommons.org/licenses/by/4.0/.

\section{References}

Alderden M, Skogan WG (2012) The place of civilians in policing. Policing: Int J Police Strat Manag 37(2):259-284

Bentley P (2013) Objectification of the Subject through the Exercise of Power: An Ethnographical Inquiry of Power in an American Policing Organization. [Unpublished doctoral dissertation] Arizona State University

Carleton RN, Afifi TO, Turner S, Taillieu T, Duranceau S, LeBouthillier DM et al (2018) Mental Disorder Symptoms among Public Safety Personnel in Canada. Can J Psychiatry 63(1):54-64

Carleton RN, Afifi TO, Turner S, Taillieu T, LeBouthiller DM, Duranceau S, Sareen J, Ricciardelli R, MacPhee, Krakauer R, Anderson GS, Cramm HA, Groll D, \& McCreary DR (2019) Exposures to potentially traumatic events among public safety personnel in Canada. Can J Behav Sci / Rev Can Sci Comport 51(1):37-52. https://doi.org/10.1037/cbs0000115

Chess AP (1960) Civilian employees in a police department. J Crim Law Criminol Pol Sci 50:591. https://doi.org/10.2307/1141456

Clement S, Schauman O, Graham T, Maggioni F, Evans-Lacko S, Bezborodovs N, Thornicroft G (2014) What is the impact of mental health-related stigma on help-seeking? A systematic review of quantitative and qualitative studies. Psychol Med 45(1):11-27. https://doi.org/10.1017/s0033291714000129

Conor P, Carrière S, Amey S, Marcellus S, \& Sauvé J (2020) Police resources in Canada, 2019. Statistics Canada. https://www.150. statcan.gc.ca/n1/en/pub/85-002-x/2020001/article/00015-eng. pdf?st=JUu4vN22

Council of Canadian Academies (2014) Policing Canada in the 21st Century: New policing for new challenges. https://cca-reports.ca/ wpcontent/uploads/2018/10/policing_fullreporten.pdf

Dick G, Metcalfe B (2001) Managerial factors and organisational commitment: A comparative study of police officers and civilian staff. Int J Public Sect Manag 14(2):111-128

Dimoff JK, Kelloway EK (2019) With a little help from my boss: The impact of workplace mental health training on leader behaviors and employee resource utilization. J Occup Health Psychol 24(1):4-19. https://doi.org/10.1037/ocp0000126

Haugen PT, McCrillis AM, Smid GE, Nijdam MJ (2017) Mental health stigma and barriers to mental health care for first responders: A systematic review and meta-analysis. J Psychiatr Res 94:218-229. https://doi.org/10.1016/j.jpsychires.2017.08.001 
Horsford SG (2012) Coping Experiences of 911 Communication Workers. Electronic Thesis and Dissertation Repository, 413

Howe A, Smajdor A, Stöckl A (2012) Towards an understanding of resilience and its relevance to medical training. Med Educ 46:349-356. https://doi.org/10.1111/j.1365-2923.2011.04188.x

Karaffa KM, Koch JM (2016) Stigma, pluralistic ignorance, and attitudes toward seeking mental health services among police officers. Crim Just Behav 43(6):759-777. https://doi. org/10.1177/0093854815613103

Kiedrowski J, Melchers R-F, Ruddell R, Petrunik M (2017) The Civilianization of Police in Canada. Public Safety Canada, Ottawa. https://doi.org/10.13140/RG.2.2.35759.12969

Krakauer RL, Stelnicki AM, Carleton RN (2020) Examining mental health knowledge, stigma, and service use intentions among public safety personnel. Front Psychol 11:949-956. https://doi. org/10.3389/fpsyg.2020.00949

Lentz L, Silverstone PH, Krameddine YI (2020) High rates of mental health disorders in civilian employees working in police organizations. Front Psychol 11:1031-1039. https://doi. org/10.3389/fpsyg.2020.01031

McAllister M, \& McKinnon J (2009) The importance of teaching and learning resilience in the health disciplines: a critical review of the literature. Nurse Educ Today 29:371-379. https://doi. org/10.1016/j.nedt.2008.10.011

McCarty WP, \& Skogan WG (2012) Job-related burnout among civilian and sworn police personnel. Police Q 16:66-84. https:// doi.org/10.1177/1098611112457357

Milliard B (2020) Utilization and impact of peer-support programs on police officers' mental health. Front in Psychol, Adv online publ. https://doi.org/10.3389/fpsyg.2020.01686
Public Safety Canada (2019) Supporting Canada's Public Safety Personnel: An Action Plan on Post-Traumatic Stress Injuries. Government of Canada: Ottawa, ON. Available at: https://www. publicsafety.gc.ca/cnt/rsrcs/pblctns/2019-ctn-pln-ptsi/2019-ctnpln-ptsi-en.pdf. (Accessed on 01 June 2020)

Ratcliffe J (2005) The effectiveness of police intelligence management: a New Zealand case study. Police Prac Res 6(5):435-451. https:// doi.org/10.1080/15614260500433038

Ricciardelli, R., Carleton, R.N., Mooney, T., Cramm, H. (2018). Playing the system: Structural factors potentiating mental health stigma, challenging awareness, and creating barriers to care for Canadian public safety personnel. Health 24(3):259-278. https:// doi.org/10.1177/1363459318800167

Ricciardelli R, Czarnuch S, Carleton RN, Gacek J, \& Shewmake J (2020) Canadian Public Safety Personnel and occupational stressors: How PSP interpret stressors on duty. Int J Environ Res Pub Health 17(13):4736. https://doi.org/10.3390/ijerph17134736

Ruddell R, Jones NA (2014) Five Years into the Great Recession. Regina, SK, Collaborative Centre for Justice and Safety

Taylor GC, Fraser S, Adam P, Sergeant L, Brian W, \& Polydore S (2006) Civilianization in the Vancouver Police Department. Available at: https://vancouver.ca/police/assets/pdf/studies/vpdstudy-civilianization.pdf (Accessed on 01 June 2020)

Walker G, Bryant W (2013) Peer support in adult mental health services. Psychiatr Rehabil J 36(1):28-34. https://doi.org/10.1037/ h0094744

Publisher's Note Springer Nature remains neutral with regard to jurisdictional claims in published maps and institutional affiliations. 